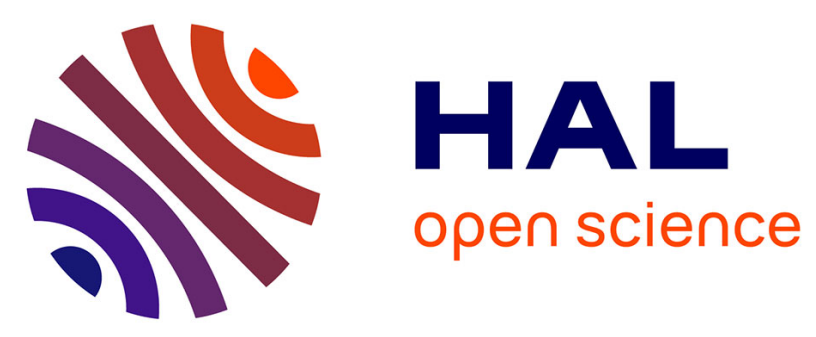

\title{
Small-scale volcanic aerosols variability, processes and direct radiative impact at Mount Etna during the EPL-RADIO/REFLECT campaigns
}

Pasquale Sellitto, Giuseppe Salerno, Alessandro La Spina, Tommaso

Caltabiano, Simona Scollo, Antonella Boselli, Giuseppe Leto, Ricardo Zanmar Sanchez, Alessia Sannino, Suzanne Crumeyrolle, et al.

\section{To cite this version:}

Pasquale Sellitto, Giuseppe Salerno, Alessandro La Spina, Tommaso Caltabiano, Simona Scollo, et al.. Small-scale volcanic aerosols variability, processes and direct radiative impact at Mount Etna during the EPL-RADIO/REFLECT campaigns. EGU General Assembly 2020, May 2020, Vienne, Austria. 10.5194/egusphere-egu2020-8337 . insu-02891851

\section{HAL Id: insu-02891851 \\ https://hal-insu.archives-ouvertes.fr/insu-02891851}

Submitted on 7 Feb 2022

HAL is a multi-disciplinary open access archive for the deposit and dissemination of scientific research documents, whether they are published or not. The documents may come from teaching and research institutions in France or abroad, or from public or private research centers.
L'archive ouverte pluridisciplinaire HAL, est destinée au dépôt et à la diffusion de documents scientifiques de niveau recherche, publiés ou non, émanant des établissements d'enseignement et de recherche français ou étrangers, des laboratoires publics ou privés. 
EGU2020-8337

https://doi.org/10.5194/egusphere-egu2020-8337

EGU General Assembly 2020

(c) Author(s) 2022. This work is distributed under

the Creative Commons Attribution 4.0 License.

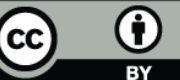

\section{Small-scale volcanic aerosols variability, processes and direct radiative impact at Mount Etna during the EPL-RADIO/REFLECT campaigns}

Pasquale Sellitto ${ }^{1}$, Giuseppe Salerno ${ }^{2}$, Alessandro La Spina ${ }^{2}$, Tommaso Caltabiano ${ }^{2}$, Simona Scollo ${ }^{2}$, Antonella Boselli ${ }^{3}$, Giuseppe Leto ${ }^{4}$, Ricardo Zanmar Sanchez ${ }^{4}$, Alessia Sannino ${ }^{5}$, Suzanne Crumeyrolle ${ }^{6}$, Benjamin Hanoune ${ }^{7}$, Chiara Giorio ${ }^{8}$, Salvatore Giammanco ${ }^{2}$, Tjarda Roberts ${ }^{9}$, Alcide di Sarra ${ }^{10}$, Bernard Legras ${ }^{11}$, and Pierre Briole ${ }^{12}$

'Laboratoire Interuniversitaire des Systèmes Atmosphériques, Université Paris-Est Créteil, France (pasquale.sellitto@lisa.upec.fr)

${ }^{2}$ Istituto Nazionale di Geofisica e Vulcanologia, Osservatorio Etneo, Catania, Italy

${ }^{3}$ Consiglio Nazionale delle Ricerche, Istituto di Metodologie per I'Analisi Ambientale, Tito Scalo (Potenza), Italy

${ }^{4}$ Istituto Nazionale di AstroFisica. INAF Osservatorio Astrofisico di Catania, Catania, Italy

${ }^{5}$ Dipartimento di Fisica, Università degli Studi di Napoli Federico II, Naples, Italy

${ }^{6}$ Université de Lille, UMR CNRS 8518 - LOA - Laboratoire d'Optique Atmosphérique, Lille, France

7Université de Lille, UMR CNRS 8522 - PC2A - Physico-Chimie des Processus de Combustion et de l'Atmosphère, Lille, France ${ }^{8}$ Dipartimento di Scienze Chimiche, Università degli Studi di Padova, Padua, Italy

'Laboratoire de Physique et Chimie de l'Environnement et de l'Espace - LPCEE, UMR 7328, CNRS-Université d'Orléans,

Orléans, France

${ }^{10}$ ENEA, Laboratory for Observations and Analyses of the Earth and Climate (SSPT-PROTER-OAC), Rome, Italy

${ }^{11}$ Laboratoire de Météorologie Dynamique - LMD, UMR CNRS 8539, École Normale Supérieure, Institut Pierre Simon

Laplace, Paris, France

${ }^{12}$ Laboratoire de Géologie, École Normale Supérieure, Paris, France

The aerosol properties of Mount Etna's passive degassing plume and its short-term processes and radiative impact were studied in detail during the EPL-RADIO/REFLECT campaigns (summer 2016, 17 and 19), using a synergistic combination of remote-sensing and in situ observations, and radiative transfer modelling. Summit observations show extremely high particulate matter concentrations, with no evidence of secondary sulphate aerosols (SA) formation. Marked indications of secondary SA formation, i.e. by the conversion of volcanic SO2 emissions, are found at larger spatial scales ( $<20 \mathrm{~km}$ downwind craters). Using portable photometers, the first mapping of small-scale spatial variability of the average size and burden of volcanic aerosols is obtained, as well as different longitudinal, perpendicular and vertical sections. A substantial variability of the plume properties is found at these spatial scales, revealing that processes (e.g. new particle formation and coarse aerosols sedimentation) are at play, which are not represented with current regional scale modelling and satellite observations. Vertical structures of typical passive degassing plumes are also obtained using observations from a fixed LiDAR station constrained with quasisimultaneous photometric observations. These observations are used as input to radiative 
transfer calculations, to obtain the shortwave top of the atmosphere (TOA) and surface radiative effects of the plume. Moreover, the radiative impact of Mount Etna's emissions is studied using a medium-term time series (a few months during summer 2019) of coupled aerosol optical properties and surface radiative flux at a fixed station on Etna's eastern flank. These are the first available estimations in the literature of the radiative impact of a passive degassing volcanic plume and are here critically discussed. Cases of co-existent volcanic aerosol layers and aerosols from other sources (Saharan dust transport events, wildfire from South Italy and marine aerosols) are also presented and discussed. 